NASA/TM-2008-215298

\title{
Identifying Bearing Rotordynamic Coefficients Using an Extended Kalman Filter
}

Brad A. Miller

Harding University, Searcy, Arkansas

Samuel A. Howard

Glenn Research Center, Cleveland, Ohio 


\section{NASA STI Program . . . in Profile}

Since its founding, NASA has been dedicated to the advancement of aeronautics and space science. The NASA Scientific and Technical Information (STI) program plays a key part in helping NASA maintain this important role.

The NASA STI Program operates under the auspices of the Agency Chief Information Officer. It collects, organizes, provides for archiving, and disseminates NASA's STI. The NASA STI program provides access to the NASA Aeronautics and Space Database and its public interface, the NASA Technical Reports Server, thus providing one of the largest collections of aeronautical and space science STI in the world. Results are published in both non-NASA channels and by NASA in the NASA STI Report Series, which includes the following report types:

- TECHNICAL PUBLICATION. Reports of completed research or a major significant phase of research that present the results of NASA programs and include extensive data or theoretical analysis. Includes compilations of significant scientific and technical data and information deemed to be of continuing reference value. NASA counterpart of peer-reviewed formal professional papers but has less stringent limitations on manuscript length and extent of graphic presentations.

- TECHNICAL MEMORANDUM. Scientific and technical findings that are preliminary or of specialized interest, e.g., quick release reports, working papers, and bibliographies that contain minimal annotation. Does not contain extensive analysis.

- CONTRACTOR REPORT. Scientific and technical findings by NASA-sponsored contractors and grantees.

- CONFERENCE PUBLICATION. Collected papers from scientific and technical conferences, symposia, seminars, or other meetings sponsored or cosponsored by NASA.

- SPECIAL PUBLICATION. Scientific, technical, or historical information from NASA programs, projects, and missions, often concerned with subjects having substantial public interest.

- TECHNICAL TRANSLATION. Englishlanguage translations of foreign scientific and technical material pertinent to NASA's mission.

Specialized services also include creating custom thesauri, building customized databases, organizing and publishing research results.

For more information about the NASA STI program, see the following:

- Access the NASA STI program home page at http://www.sti.nasa.gov

- E-mail your question via the Internet to help@ sti.nasa.gov

- Fax your question to the NASA STI Help Desk at 301-621-0134

- Telephone the NASA STI Help Desk at 301-621-0390

- Write to: NASA Center for AeroSpace Information (CASI) 7115 Standard Drive Hanover, MD 21076-1320 
NASA/TM—2008-215298

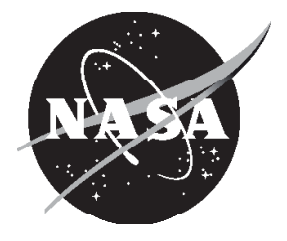

\section{Identifying Bearing Rotordynamic Coefficients Using an Extended Kalman Filter}

Brad A. Miller

Harding University, Searcy, Arkansas

Samuel A. Howard

Glenn Research Center, Cleveland, Ohio

National Aeronautics and

Space Administration

Glenn Research Center

Cleveland, Ohio 44135 


\section{Acknowledgments}

The material is based upon work supported by NASA under award no. NNC06GA20G.

Level of Review: This material has been technically reviewed by technical management.

Available from

NASA Center for Aerospace Information

7115 Standard Drive

Hanover, MD 21076-1320
National Technical Information Service 5285 Port Royal Road Springfield, VA 22161

Available electronically at http://gltrs.grc.nasa.gov 


\title{
Identifying Bearing Rotordynamic Coefficients Using an Extended Kalman Filter
}

\author{
Brad A. Miller \\ Harding University \\ Searcy, Arkansas 72149-2290 \\ Samuel A. Howard \\ National Aeronautics and Space Administration \\ Glenn Research Center \\ Cleveland, Ohio 44135
}

\begin{abstract}
An Extended Kalman Filter is developed to estimate the linearized direct and indirect stiffness and damping force coefficients for bearings in rotordynamic applications from noisy measurements of the shaft displacement in response to imbalance and impact excitation. The bearing properties are modeled as stochastic random variables using a Gauss-Markov model. Noise terms are introduced into the system model to account for all of the estimation error, including modeling errors and uncertainties and the propagation of measurement errors into the parameter estimates. The system model contains two userdefined parameters that can be tuned to improve the filter's performance; these parameters correspond to the covariance of the system and measurement noise variables. The filter is also strongly influenced by the initial values of the states and the error covariance matrix. The filter is demonstrated using numerically simulated data for a rotor-bearing system with two identical bearings, which reduces the number of unknown linear dynamic coefficients to eight. The filter estimates for the direct damping coefficients and all four stiffness coefficients correlated well with actual values, whereas the estimates for the cross-coupled damping coefficients were the least accurate.
\end{abstract}

\section{Introduction}

Compliant surface foil air bearings are self-acting hydrodynamic bearings that support a rotating shaft on a thin layer of gas between the shaft surface and a sheet metal foil supported by a series of stiff bump foils (see fig. 1). Advancements in coating materials and methods to design the supporting bump foil system have increased the load bearing capacity in gas foil bearings (DellaCorte and Valco, 2000) and improved their stiffness and damping properties (Salehi et al., 2004) and their ability to operate in high temperature environments (DellaCorte et al., 1999; Heshmat et al., 2007). These advancements have made gas foil journal bearings prime candidates for implementation in new applications critical to NASA's mission, such as systems to convert nuclear energy to electricity for power generation in space and more efficient, lower maintenance propulsion systems for aeronautics. Additionally, gas foil bearings are increasingly being considered and used in commercial applications such as microturbine generators and industrial blowers. Coupled with these materials and design advancements is the need for experimentally verified tools for predicting steady state performance and rotordynamic properties of gas foil bearings. The capability to measure the linearized rotordynamic properties of actual gas foil bearings is necessary to validate and calibrate theoretically predictive tools and to boost the confidence that highspeed rotordynamic machinery utilizing these components will operate effectively and reliably. 


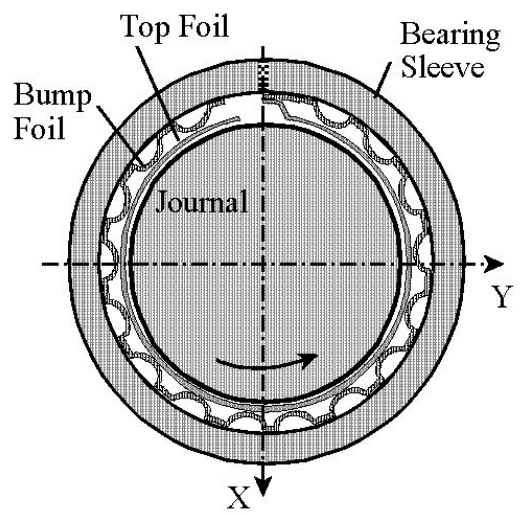

Figure 1.-Cross section of a gas foil journal bearing.

Knowledge of the bearing dynamic properties is instrumental in predicting the performance characteristics of high speed turbo machinery. As a shortcut to completely modeling the physics of the bearing, the bearings are simply represented by linearized springs and dampers, in which case the challenge then becomes to estimate the linearized force coefficients for these components. Bearing reaction forces in this form are most convenient for analyses involving the whole rotor-bearing system for which each bearing is just one of many integrated components.

Several discrete-time domain and frequency domain techniques have been presented in the literature for estimating the linearized stiffness and damping (and inertia) coefficients for bearings and seals. Tiwari et al. (2004) provides a review of the literature on the topic. Discrete-time domain methods, which generally utilize least-squares estimators, often suffer from the disadvantages that the bearing estimates are biased and highly sensitive to measurement noise and errors introduced by transforming the continuous time model into a discrete-time model (Sahinkaya and Burrows, 1984). These problems are mostly overcome, resulting in improved bearing parameter predictions, by employing estimation methods in the frequency domain. Most of the methods discussed in the literature estimate the unknown bearing parameters using motion measurements from systems that are excited by some form of known external forcing, e.g., shakers or impacts. Experimental systems with the capability for external excitation from shakers are costly and generally limited to the laboratory, whereas many rotating machinery in use are instrumented with shaft displacement sensors and housing accelerometers for condition monitoring purposes. For systems without the capability of external harmonic excitation, estimation methods have been developed that rely on imbalance response measurements or the response from impact excitation. The system of equations generated by imbalance excitation tends to be ill-conditioned, especially if the orbit is near circular (Roberts et al., 1990; Murphy and Wagner, 1991), and the results from these methods often show considerable scatter (Tiwari et al., 2004, De Santiago and San Andrés, 2007b). Bearing identification from impact excitation has demonstrated promising results (Qiu and Tieu, 1997; Tiwari et al., 2004, De Santiago and San Andrés, 2007a). Also, Howard et al. (2001) determined direct bearing dynamic stiffness and damping coefficients for a gas foil journal bearing at the system natural frequency by measuring the free vertical displacement of the shaft in response to an impact excitation. The system natural frequency provided the stiffness estimate, and the damping was estimated from the decay rate.

The objective of this paper is to demonstrate the application of an Extended Kalman Filter (EKF) to estimate eight linearized rotordynamic (stiffness and damping) force coefficients for bearings from measurements of the system response to imbalance and impact excitation. The EKF is a time domain filter that provides an efficient recursive algorithm for estimating states in a nonlinear dynamical system from noisy measurements. In this application, the dynamical system states to be estimated must include the bearing stiffness and damping properties, which results in a system governing equation that is a nonlinear function of the states. As a consequence, the estimation algorithm will employ the Extended Kalman Filter instead of the traditional Kalman Filter, which is used for linear systems. Fritzen and 
Seibold (1990) have successfully applied the EKF to identify the damping factor and depth parameter for a simple rotor with a cracked shaft and the inertia, damping and stiffness coefficients for annular seals in a high pressure turbopump test rig.

\section{Dynamic Model of the Shaft and Bearings}

A schematic of the rotor-bearing system is shown in figure 2. The shaft layout is chosen to match the rotordynamic simulator facility at NASA's Glenn Research Center shown in figure 3 (Howard, 2007). In future work, the principles developed in the current paper will be applied and compared to experimental data obtained from the rotordynamic simulator facility. The ratio of the shaft radius to length is relatively large, so the rotor is assumed to be rigid. The rotor displacement is represented by four coordinates: $x_{1}$ and $y_{1}$ correspond, respectively, to horizontal and vertical displacements from equilibrium $\left(x_{10}\right.$ and $y_{10}$, respectively) of the shaft at the center of the bearing located near the turbine disk, and $x_{2}$ and $y_{2}$ are similar shaft displacements from equilibrium ( $x_{20}$ and $y_{20}$, respectively) at the bearing near the thrust bearing plate. The linearized bearing model includes only the elastic and dissipative effects; inertial effects are ignored. The $x$ and $y$ direction bearing forces $\left(f_{b x}\right.$ and $f_{b y}$, respectively) on the shaft are

$$
\left\{\begin{array}{l}
f_{b x, i} \\
f_{b y, i}
\end{array}\right\}=-\left[\begin{array}{ll}
k_{x x} & k_{x y} \\
k_{y x} & k_{y y}
\end{array}\right]\left\{\begin{array}{c}
x_{i} \\
y_{i}
\end{array}\right\}-\left[\begin{array}{cc}
c_{x x} & c_{x y} \\
c_{y x} & c_{y y}
\end{array}\right]\left\{\begin{array}{c}
\dot{x}_{i} \\
\dot{y}_{i}
\end{array}\right\} \quad i=1,2 .
$$

The bearings are assumed to be identical, so they are modeled with the same rotordynamic coefficients, which minimizes the number of parameters to be estimated to a total of eight, four direct $\left(k_{x x}, k_{y y}, c_{x x}\right.$, and $\left.c_{y y}\right)$ and four cross-coupled $\left(k_{x y}, k_{y x}, c_{x y}\right.$, and $\left.c_{y x}\right)$ coefficients.

The linearized equations of motion for the shaft can be expressed as

$$
\mathbf{M} \ddot{\mathbf{z}}+(\mathbf{C}+\Omega \mathbf{G}) \dot{\mathbf{z}}+\mathbf{K z}=\mathbf{F}_{0}(t),
$$

where $\mathbf{z}=\left\{x_{1}, y_{1}, x_{2}, y_{2}\right\}^{T}, \mathbf{z}(t=0)=\mathbf{z}_{0}$, and $\dot{\mathbf{z}}(t=0)=\dot{\mathbf{z}}_{0}$. The mass and gyroscopic matrices, $\mathbf{M}$ and G, respectively, are

$$
\mathbf{M}=\frac{1}{L^{2}}\left[\begin{array}{cccc}
m l_{2}^{2}+I_{t} & 0 & m l_{1} l_{2}-I_{t} & 0 \\
0 & m l_{2}^{2}+I_{t} & 0 & m l_{1} l_{2}-I_{t} \\
m l_{1} l_{2}-I_{t} & 0 & m l_{1}^{2}+I_{t} & 0 \\
0 & m l_{1} l_{2}-I_{t} & 0 & m l_{1}^{2}+I_{t}
\end{array}\right] \text { and } \mathbf{G}=\frac{1}{L^{2}}\left[\begin{array}{cccc}
0 & I_{p} & 0 & -I_{p} \\
-I_{p} & 0 & I_{p} & 0 \\
0 & -I_{p} & 0 & I_{p} \\
I_{p} & 0 & -I_{p} & 0
\end{array}\right] .
$$

where $L=l_{1}+l_{2}$. Likewise, the stiffness and damping matrices, $\mathbf{S}$ and $\mathbf{C}$, respectively, are

$$
\mathbf{S}=\left[\begin{array}{cccc}
k_{x x} & k_{x y} & 0 & 0 \\
k_{y x} & k_{y y} & 0 & 0 \\
0 & 0 & k_{x x} & k_{x y} \\
0 & 0 & k_{y x} & k_{y y}
\end{array}\right] \text { and } \mathbf{C}=\left[\begin{array}{cccc}
c_{x x} & c_{x y} & 0 & 0 \\
c_{y x} & c_{y y} & 0 & 0 \\
0 & 0 & c_{x x} & c_{x y} \\
0 & 0 & c_{y x} & c_{y y}
\end{array}\right]
$$




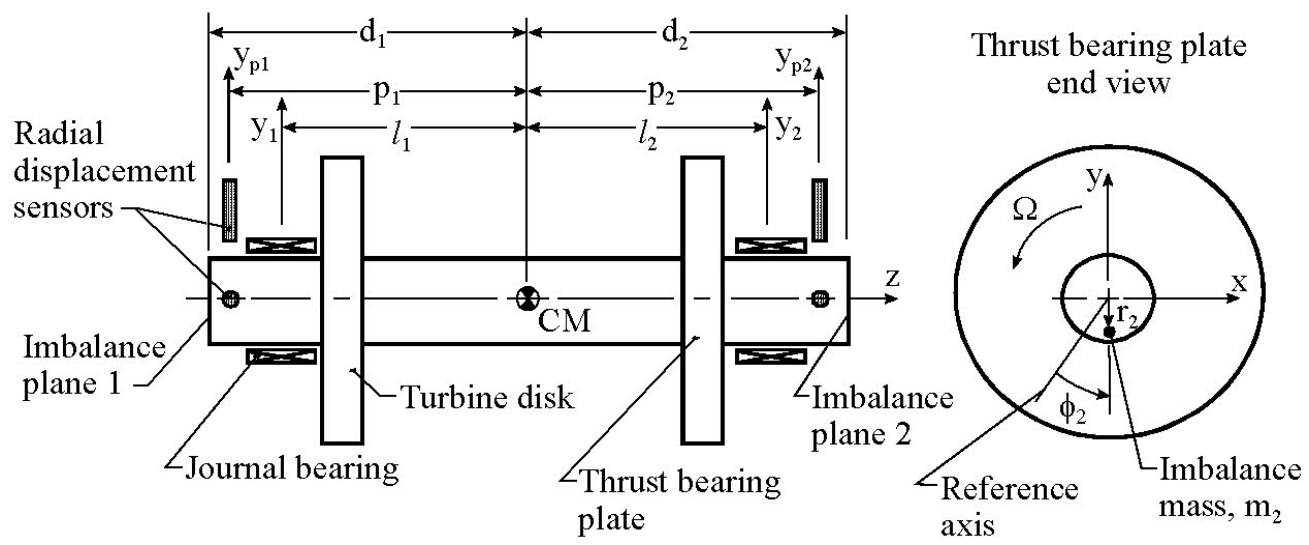

Figure 2.-Schematic of the rotor-bearing system.

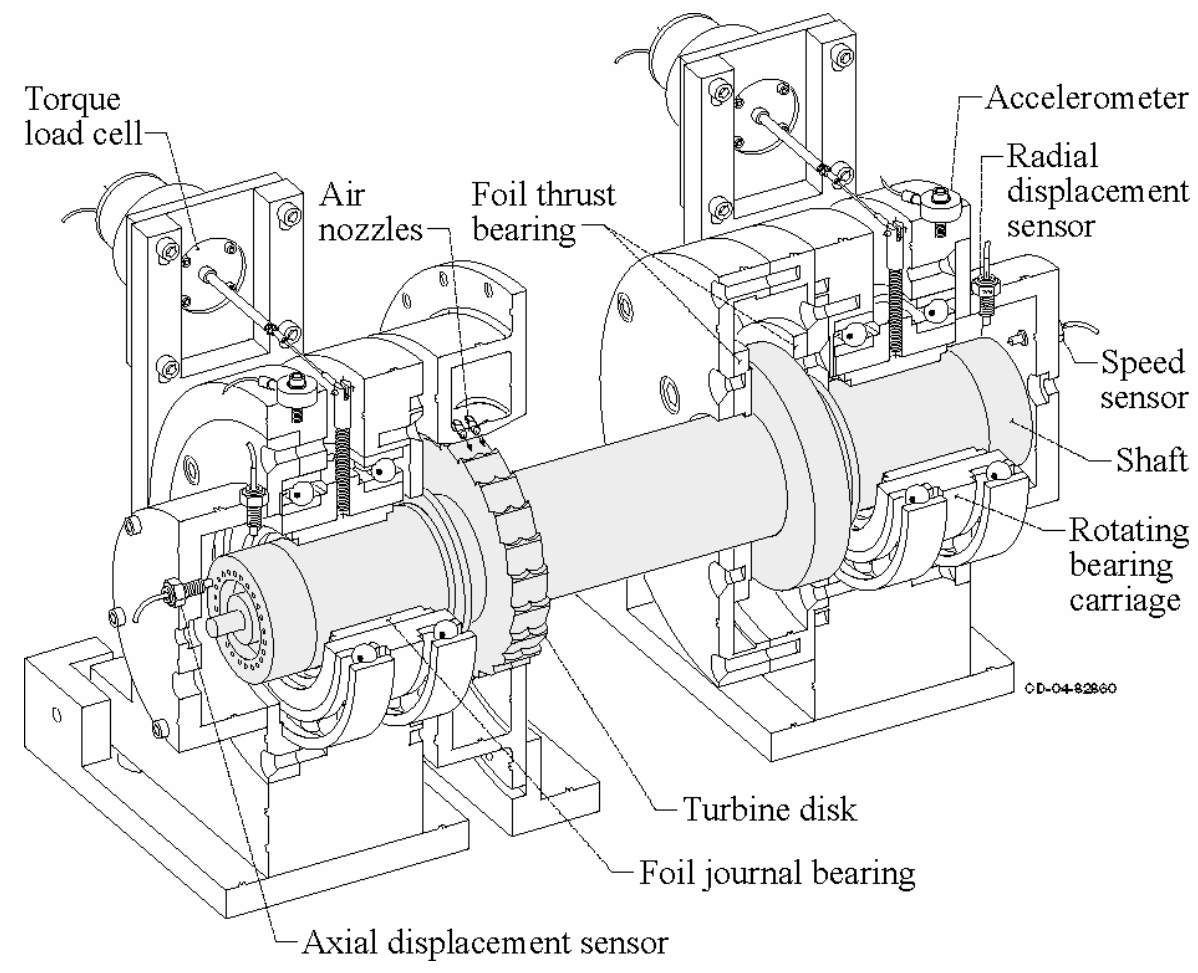

Figure 3.-Schematic of the NASA Glenn Research Center rotordynamic simulator test rig.

The forcing terms in the equations of motion result from the effects of imbalance and impact excitation. Imbalances $m_{1} r_{1}$ and $m_{2} r_{2}$ are oriented at angles of $\phi_{1}$ and $\phi_{2}$, respectively, in planes located at $d_{1}$ and $d_{2}$, respectively, from the center of mass. Likewise, an external impact force with $x$ and $y$ components, respectively, of $f_{x}$ and $f_{y}$, acts at a distance of $z_{p}$ from the center of mass toward the thrust bearing plate, leading to 


$$
\mathbf{F}_{0}(t)=\left\{\begin{array}{l}
m_{1} r_{1} \Omega^{2}\left(\frac{l_{2}+d_{1}}{L}\right) \cos \left(\Omega t+\phi_{1}\right)+m_{2} r_{2} \Omega^{2}\left(\frac{l_{2}-d_{2}}{L}\right) \cos \left(\Omega t+\phi_{2}\right) \\
m_{1} r_{1} \Omega^{2}\left(\frac{l_{2}+d_{1}}{L}\right) \sin \left(\Omega t+\phi_{1}\right)+m_{2} r_{2} \Omega^{2}\left(\frac{l_{2}-d_{2}}{L}\right) \sin \left(\Omega t+\phi_{2}\right) \\
m_{1} r_{1} \Omega^{2}\left(\frac{l_{1}-d_{1}}{L}\right) \cos \left(\Omega t+\phi_{1}\right)+m_{2} r_{2} \Omega^{2}\left(\frac{l_{1}+d_{2}}{L}\right) \cos \left(\Omega t+\phi_{2}\right) \\
m_{1} r_{1} \Omega^{2}\left(\frac{l_{1}-d_{1}}{L}\right) \sin \left(\Omega t+\phi_{1}\right)+m_{2} r_{2} \Omega^{2}\left(\frac{l_{1}+d_{2}}{L}\right) \sin \left(\Omega t+\phi_{2}\right)
\end{array}\right\}+\left\{\begin{array}{c}
f_{x}\left(\frac{l_{2}-z_{p}}{L}\right) \\
f_{y}\left(\frac{l_{2}-z_{p}}{L}\right) \\
f_{x}\left(\frac{l_{1}+z_{p}}{L}\right) \\
f_{y}\left(\frac{l_{1}+z_{p}}{L}\right)
\end{array}\right\} .
$$

The values for the imbalance represent both the residual imbalance of the shaft and any applied imbalance. The residual imbalance can be measured with a balancing machine, and the applied imbalance is assumed to be known. The impact force is also assumed to be known as a function of time, which can be achieved if the impact is performed with an instrumented impact hammer.

In most situations it is not possible to place the displacement transducers in a location so that they measure the shaft motion at the centers of the bearings. In the case when the displacement transducers are located at $p_{1}$ and $p_{2}$ from the shaft center of mass, see figure 2 , the shaft motion at the bearing centers, denoted by $x_{1}, y_{1}, x_{2}$, and $y_{2}$, can be computed from the transducer measurements, $x_{p 1}, y_{p 1}, x_{p 2}$, and $y_{p 2}$, with the following linear transformation,

$$
\left[\begin{array}{ll}
x_{1} & y_{1} \\
x_{2} & y_{2}
\end{array}\right]=\left[\begin{array}{ll}
\left(p_{2}+l_{1}\right) & \left(p_{1}-l_{1}\right) \\
\left(p_{2}-l_{2}\right) & \left(p_{1}+l_{2}\right)
\end{array}\right]\left[\begin{array}{ll}
x_{p 1} & y_{p 1} \\
x_{p 2} & y_{p 2}
\end{array}\right] .
$$

For the EKF, the bearing rotordynamic coefficients must be included as states so they can be estimated; consequently, the global state vector becomes

$$
\mathbf{s}^{T} \equiv\left\{\mathbf{s}_{v}{ }^{T}, \mathbf{s}_{z}{ }^{T}, \mathbf{r}^{T}\right\}=\left\{\dot{\mathbf{z}}^{T}, \mathbf{z}^{T}, \mathbf{r}^{T}\right\}
$$

where $\mathbf{r}$ contains the rotordynamic coefficients, such that $\mathbf{r}=\left\{c_{x x}, c_{x y}, c_{y x}, c_{y y}, k_{x x}, k_{x y}, k_{y x}, k_{y y}\right\}^{T}$. Within the framework of the EKF estimation scheme, all of the variables in the state vector, including the rotordynamic properties, will be modeled stochastically. The rotordynamic coefficients are assumed to be constant, but, realistically, the estimates will vary with time due to some random error within the measurements. The error within the estimates will be parameterized by the array of stochastic variables, $\mathbf{w}_{\mathbf{r}}$. A first-order Gauss-Markov model for the rotordynamic parameters is

$$
\dot{\mathbf{r}}=\mathbf{w}_{\mathbf{r}} .
$$

The vector $\mathbf{w}_{\mathbf{r}}$ is assumed to be Gaussian white noise with zero mean and covariance matrix $\mathbf{Q}_{\mathbf{r}}$.

Now, the equations of motion are combined with the Gauss-Markov models to form a compact, nonlinear system model,

$$
\dot{\mathbf{s}}=\left\{\begin{array}{c}
\dot{\mathbf{s}}_{v} \\
\dot{\mathbf{s}}_{z} \\
\dot{\mathbf{r}}
\end{array}\right\}=\left\{\begin{array}{c}
g\left(\mathbf{s}_{v}, \mathbf{s}_{z}, \mathbf{r}, \mathbf{F}_{0}, t\right) \\
\mathbf{s}_{v} \\
0
\end{array}\right\}+\left\{\begin{array}{l}
\mathbf{w}_{\mathbf{v}} \\
\mathbf{w}_{\mathbf{z}} \\
\mathbf{w}_{\mathbf{r}}
\end{array}\right\}=f\left(\mathbf{s}, \mathbf{F}_{\mathbf{0}}, t\right)+\mathbf{w} .
$$


Here, $\mathbf{w}_{\mathbf{v}}$ and $\mathbf{w}_{\mathbf{z}}$ also represent process noise vectors, assumed to be Gaussian white noise, with zero means and covariance matrices $\mathbf{Q}_{\mathbf{v}}$ and $\mathbf{Q}_{\mathbf{z}}$, respectively. The process noise vectors form

$\mathbf{w}^{T}=\left[\mathbf{w}_{\mathbf{v}}^{T} \mathbf{w}_{\mathbf{z}}^{T} \mathbf{w}_{\mathbf{r}}^{T}\right]$ with a corresponding covariance matrix $\mathbf{Q}$. These noise terms account for all of the error within the estimates, including modeling errors and uncertainties and the propagation of measurement errors into the estimated values. The system model can be represented as a discrete-time equation for discrete time steps $t_{k}(k=0,1,2 \ldots)$ by

$$
\mathbf{s}_{k+1}=\mathbf{s}_{k}+\int_{t_{k}}^{t_{k+1}} f\left(\mathbf{s}, \mathbf{F}_{\mathbf{0}}, t\right) d t+\mathbf{w}_{k} .
$$

Finally, an output vector, $\mathbf{y}_{k}$, is formed from discrete samples of the shaft displacement. These measurements will also be contaminated with noise, so the model for the output vector is comprised of a linear combination of the true shaft displacement states, $\mathbf{s}_{\mathbf{z} k}$, and a stochastic random noise parameter, $\mathbf{v}_{k}$, to compensate for the measurement noise, such that

$$
\mathbf{y}_{k}=\mathbf{s}_{\mathbf{z} k}+\mathbf{v}_{k}=\mathbf{H} \mathbf{s}_{k}+\mathbf{v}_{k}
$$

where $\mathbf{H}=\left[\begin{array}{lll}\mathbf{0}_{4 \times 4} & \mathbf{I}_{4 \times 4} & \mathbf{0}_{4 \times 8}\end{array}\right]$. The measurement noise parameter, $\mathbf{v}_{k}$, is assumed to be white noise with a constant covariance matrix $\mathbf{R}$.

\section{The Extended Kalman Filter (EKF)}

The EKF is a predictor-corrector type of estimation scheme that provides estimates at each time step for the states, $\hat{\mathbf{s}}_{k}$, and the error covariance matrix, $\widehat{\mathbf{P}}_{k}$. The error covariance matrix is the expected value of the error between the true states and the state estimates.

The first step in the process to project the state estimate from one time step to the next is to predict the projection based solely on the model and the old state estimate, forming intermediate predictions of the state and covariance matrix at the new time step. To distinguish between predictions and estimates at a time step, predictions of parameters are designated with the over-bar symbol and estimates are marked by an over-caret symbol. The state prediction at the new time step is computed by solving the original nonlinear governing equation, giving

$$
\overline{\mathbf{s}}_{k+1}=\hat{\mathbf{s}}_{k}+\int_{t_{k}}^{t_{k+1}} f\left(\hat{\mathbf{s}}, \mathbf{F}_{\mathbf{0}}, t\right) d t
$$

Using the "Continuous-Discrete EKF" formulation for nonlinear systems with discrete measurements, as described by Gelb (1974), the error covariance prediction is determined by

$$
\overline{\mathbf{P}}_{k+1}=\hat{\mathbf{P}}_{k}+\int_{t_{k}}^{t_{k+1}}\left(\mathbf{A} \hat{\mathbf{P}}+\hat{\mathbf{P}} \mathbf{A}^{T}+\mathbf{Q}\right) d t
$$

The time integrations in eqs. (12) and (13) are computed using an efficient high-order numerical integration scheme. The A matrix in the error covariance prediction represents a linearization of $f$ about the current estimate of the state vector,

$$
\mathbf{A}=\frac{\partial f\left(\hat{\mathbf{s}}_{k}, \mathbf{F}_{\mathbf{0} k}, t_{k}\right)}{\partial \mathbf{s}}
$$

Initial values for the state vector and error covariance matrix are set to $\hat{\mathbf{s}}_{0}$ and $\hat{\mathbf{P}}_{0}$, respectively. 
The second step is to update the state and error covariance predictions using the measurement data,

$$
\hat{\mathbf{s}}_{k+1}=\overline{\mathbf{s}}_{k+1}+\mathbf{K}_{k+1}\left(\mathbf{y}_{k+1}-\mathbf{H} \overline{\mathbf{s}}_{k+1}\right)
$$

and

$$
\hat{\mathbf{P}}_{k+1}=\left(\mathbf{I}-\mathbf{K}_{K+1} \mathbf{H}\right) \overline{\mathbf{P}}_{k+1} .
$$

The term $\mathbf{K}_{k+1}$ is known as the Kalman gain factor. The following formulation for the Kalman gain factor blends the state estimates with the measured data in a manner that minimizes the error covariance (Friedland, 1986),

$$
\mathbf{K}_{k+1}=\overline{\mathbf{P}}_{k+1} \mathbf{H}^{T}\left(\mathbf{H} \overline{\mathbf{P}}_{k+1} \mathbf{H}^{T}+\mathbf{R}\right)^{-1}
$$

Equations (12) to (17) are repeated at consecutive time steps corresponding to each discrete measurement, providing sequential, filtered estimates of the shaft displacement variables, their derivatives, and the rotordynamic coefficients.

Though the EKF is relatively simple and computationally similar to the traditional linear Kalman filter, there are well-known drawbacks (Julier and Uhlmann, 1997). The filter is prone to divergence if the underlying dynamical system is significantly nonlinear over the discrete time step, and the error covariance is often estimated poorly, which degrades performance and can cause divergence. Some researchers, including Julier and Uhlmann (1997), have developed improved algorithms similar to the EKF that are not limited by these issues.

\section{Estimating Bearing Properties in a Rotor-Bearing System}

The EKF will be applied to estimate the rotordynamic properties of two bearings in the rotor-bearing system depicted in figure 2 . The bearings are assumed to have identical properties, which reduces the number of parameters to be estimated from sixteen to eight. As mentioned earlier, the geometry and operating parameters of the rotor-bearing system are chosen to be representative of NASA's rotordynamic simulator test rig and are listed in table 1, and the assumed stiffness and damping properties of the bearings listed in table 2 are thought to be realistic values for the chosen operating conditions. Shaft motion can be excited by the applied imbalance at the shaft ends or by impact or by both. In any case, the applied imbalance and the impact force are assumed to be known. The EKF algorithm will be tested by numerical simulation in which the "experimental" data for the shaft motion is generated by numerically solving the equations of motion, eq. (2), and then adding uncorrelated white noise with zero mean and 1.0 $\mu \mathrm{m}$ standard deviation to simulate measurement noise.

TABLE 1.-PARAMETERS OF THE ROTOR-BEARING SYSTEM

\begin{tabular}{|l|l|l|l|}
\hline$l_{1}, l_{2}$ & $0.1245 \mathrm{~m}$ & $\Omega$ & $20000 \mathrm{rpm}$ \\
\hline$d_{1}, d_{2}$ & $0.1661 \mathrm{~m}$ & $r_{1}, r_{2}$ & $18.42 \mathrm{~mm}$ \\
\hline $\mathbf{M}$ & $3.089 \mathrm{~kg}$ & $m_{1}, m_{2}$ & $0.5 \mathrm{~g}$ \\
\hline$I_{p}$ & $2.629 \times 10^{-3} \mathrm{~kg} \cdot \mathrm{m}^{2}$ & $\phi_{1}$ & $0^{\circ}$ \\
\hline$I_{t}$ & $2.483 \times 10^{-2} \mathrm{~kg} \cdot \mathrm{m}^{2}$ & $\phi_{2}$ & $90^{\circ}$ \\
\hline
\end{tabular}


TABLE 2.-STIFFNESS AND DAMPING PROPERTIES ASSUMED FOR THE BEARINGS

\begin{tabular}{|l|c|l|c|}
\hline$k_{x x}$ & $500 \mathrm{kN} / \mathrm{m}$ & $c_{x x}$ & $1,100 \mathrm{~N} \cdot \mathrm{s} / \mathrm{m}$ \\
\hline$k_{x y}$ & $400 \mathrm{kN} / \mathrm{m}$ & $c_{x y}$ & $50 \mathrm{~N} \cdot \mathrm{s} / \mathrm{m}$ \\
\hline$k_{y x}$ & $-350 \mathrm{kN} / \mathrm{m}$ & $c_{y x}$ & $-40 \mathrm{~N} \cdot \mathrm{s} / \mathrm{m}$ \\
\hline$k_{y y}$ & $600 \mathrm{kN} / \mathrm{m}$ & $c_{y y}$ & $1,200 \mathrm{~N} \cdot \mathrm{s} / \mathrm{m}$ \\
\hline
\end{tabular}

The performance of the EKF filter is largely affected by the values of user-defined tuning parameters and the initial estimates of the state and error covariance matrix. The $\mathbf{Q}$ and $\mathbf{R}$ matrices model the process noise and measurement noise, respectively. More process noise indicates to the filter that a greater difference exists between the filter model and the real process. Likewise, larger values in $\mathbf{R}$ indicate the presence of more error in the measurements. In general, these quantities can vary with time, but in this analysis, they are assumed to be constant. Their values are set by the user, and they are generally used as tuning parameters, especially for the EKF. The filter performance is also a function of the initial estimates of the state and error covariance matrix. Larger initial values of the error covariance matrix represent a greater uncertainty in the initial state estimates.

In this application, the values of the process and noise matrices were tuned by a trial and error procedure. The EKF filter was generally insensitive to the values of the process noise for the rotordynamic coefficients, $\mathbf{Q}_{\mathbf{r}}$, so it was set to zero, i.e., $\mathbf{Q}_{\mathbf{r}}=\mathbf{0}$. Also, the filter worked best for zero values of the process noise for the state variables, i.e., $\mathbf{Q}_{\mathbf{v}}=\mathbf{Q}_{\mathbf{z}}=\mathbf{0}$, which is expected since the experimental data was generated with a model that is identical to the filter model. The trial and error procedure indicated that values for the diagonal elements of $\mathbf{R}$ between 0.2 and $2.0 \mu \mathrm{m}$ produced acceptable results for the amount of measurement noise, so the diagonal elements of the measurement noise covariance matrix were set to $\mathbf{R}=\operatorname{diag}\left[\begin{array}{llll}1.0 & 1.0 & 1.0 & 1.0\end{array}\right] \mu \mathrm{m}$.

The filter was much more sensitive to the initial estimates of the states and error covariance matrix than to $\mathbf{Q}$ and $\mathbf{R}$. Initial estimates for the states were chosen to be

$$
\hat{\mathbf{r}}_{0}=\left\{900 \frac{N \cdot s}{m}, 0,0,900 \frac{N \cdot s}{m}, 3 \times 10^{5} \frac{N}{m}, 3 \times 10^{5} \frac{N}{m},-3 \times 10^{5} \frac{N}{m}, 3 \times 10^{5} \frac{N}{m}\right\}^{T},
$$

and the initial error covariance matrix was set to be a diagonal matrix with elements of

$$
\operatorname{diag}\left(\hat{\mathbf{P}}_{0}\right)=\left\{10^{6} \frac{N^{2} \cdot s^{2}}{m^{2}}, 10^{6} \frac{N^{2} \cdot s^{2}}{m^{2}}, 10^{6} \frac{N^{2} \cdot s^{2}}{m^{2}}, 10^{6} \frac{N^{2} \cdot s^{2}}{m^{2}}, 10^{11} \frac{N^{2}}{m^{2}}, 10^{11} \frac{N^{2}}{m^{2}}, 10^{11} \frac{N^{2}}{m^{2}}, 10^{11} \frac{N^{2}}{m^{2}}\right\} .
$$

\section{Results}

In each of the simulations that follow, the motion is simulated for $0.125 \mathrm{~s}$, or approximately 41.7 shaft revolutions, with a time step of $50 \mu \mathrm{s}$. The shaft originates from its equilibrium position with zero initial velocity. The first $30 \mathrm{~ms}$ of data made available for processing through the EKF is removed to eliminate the transients due to the initial conditions.

For the first numerical simulation, the shaft motion was excited by both applied imbalance and impact. The imbalance is listed in Table 1 , and the impact consisted of a constant force $f_{y}=-515 \mathrm{~N}$ acting at the shaft mass center $\left(z_{p}=0\right)$, initiating at $40 \mathrm{~ms}$ and enduring for $50 \mu \mathrm{s}$. Figure 4 plots the percent error between the estimated coefficients and the actual values as a function of the time step for one representative simulation. Within $30 \mathrm{~ms}$, the estimates for all but the cross-coupled damping reached steady state, with errors less than 0.5 percent for the direct damping and less than 5.5 percent for the stiffness terms. The errors for the cross-coupled damping varied much more significantly. This result is common among the parameter identification methods (De Santiago and San Andrés, 2007a and 2007b). In 


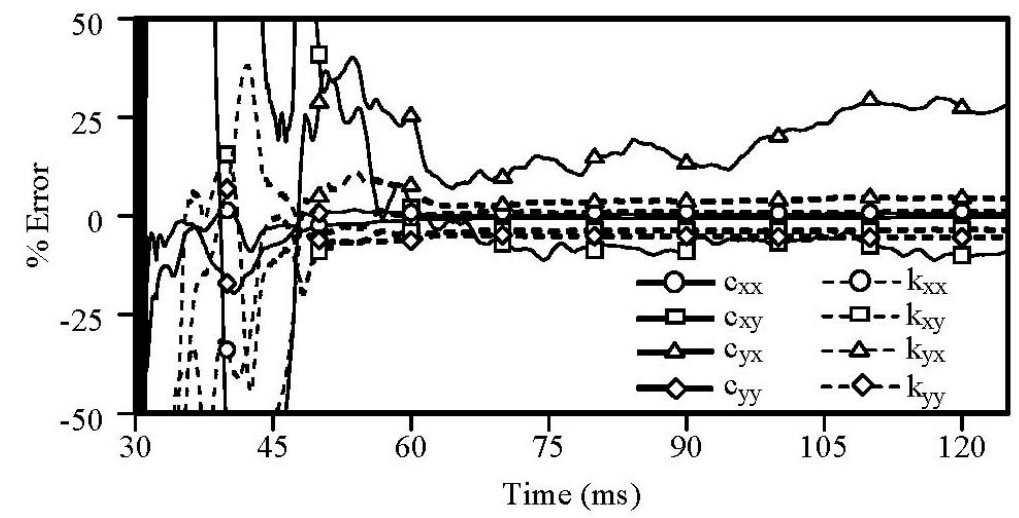

Figure 4.--Percent error in the estimated rotordynamic coefficients for a representative simulation. The shaft was excited by imbalance and impact.

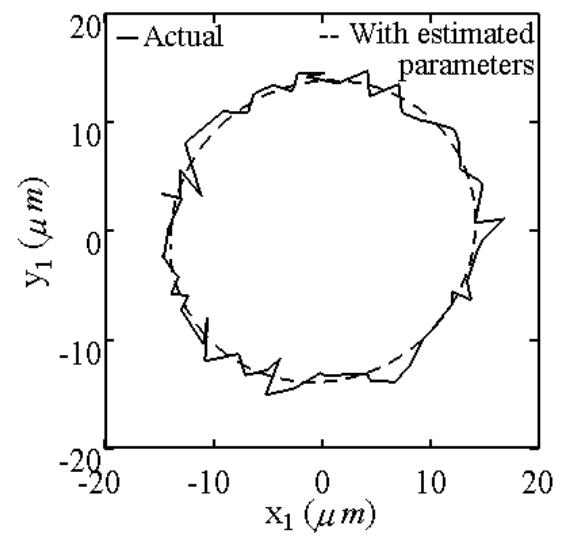

Figure 5.-One full cycle of the orbit at the turbine end. Data shown includes the actual noisy "experimental" orbit and the orbit simulated with the rotordynamic properties estimated from the simulation with both imbalance and impact excitation.

general, the EKF algorithm improves with better initial guesses, so it is possible to use the EKF iteratively, especially if the estimates do not reach steady state in one filtering pass. In such a case, the final estimates from one pass through the filter would be used as the initial guesses for the next pass. This process is repeated until eventually the change in the final estimates is below some tolerance. In the present case, iteration did not improve the estimates significantly.

Figure 5 shows a comparison between the orbit from a simulation using the estimated bearing properties and the actual noisy orbit data. One may be tempted to use this comparison as a check to verify the accuracy of the parameter estimates since the luxury of comparing the estimated bearing properties with the actual bearing properties will not generally be available. The logic is that a favorable orbit comparison indicates success of the identification scheme. In this case, the orbits match very closely, apparently indicating that the parameter identification was successful. The problem, however, is that the quality of the orbit prediction is not closely tied to the accuracy of each system parameter individually. Data presented later will show rather close orbits predicted using bearing parameters that are significantly in error compared to the actual values.

Table 3 lists the results of the EKF applied to twenty numerical simulations where the shaft was excited by imbalance and impact. Considering the amount of noise in the data, the direct damping estimates were exceptional, the estimates of the four stiffness terms were reasonable, but the cross- 
coupled damping estimates showed significant error. The deviation in the estimates (represented by the percent standard deviation relative to the actual parameter values) also followed the same trends. The cross-coupled damping estimates showed the largest relative variance, which is comparable to other estimation methods (Tiwari et al., 2004, De Santiago and San Andrés, 2007b).

TABLE 3.-AVERAGE ESTIMATED ROTORDYNAMIC COEFFICIENTS FROM 20 SIMULATIONS

\begin{tabular}{|c|c|c|c|c|c|c|}
\hline Parameter & Unit & $\begin{array}{c}\text { Exact } \\
\text { value }\end{array}$ & $\begin{array}{c}\text { EKF } \\
\text { estimate }\end{array}$ & $\begin{array}{c}\text { Standard } \\
\text { deviation }\end{array}$ & $\begin{array}{c}\text { Percent } \\
\text { error }\end{array}$ & $\begin{array}{c}\text { Percent standard } \\
\text { deviation }\end{array}$ \\
\hline$c_{x x}$ & $\mathrm{~N} \cdot \mathrm{s} / \mathrm{m}$ & 1100 & 1095.0 & 9.2 & -0.455 & 0.840 \\
\hline$c_{x y}$ & $\mathrm{~N} \cdot \mathrm{s} / \mathrm{m}$ & 50 & 39.6 & 9.3 & -20.8 & 18.6 \\
\hline$c_{y x}$ & $\mathrm{~N} \cdot \mathrm{s} / \mathrm{m}$ & -40 & -73.4 & 11.2 & 83.5 & 28.0 \\
\hline$c_{y y}$ & $\mathrm{~N} \cdot \mathrm{s} / \mathrm{m}$ & 1200 & 1208.3 & 13.5 & 0.692 & 1.13 \\
\hline$k_{x x}$ & $\mathrm{~N} / \mathrm{m}$ & 500,000 & 520,094 & 21,644 & 4.02 & 4.33 \\
\hline$k_{x y}$ & $\mathrm{~N} / \mathrm{m}$ & 400,000 & 388,402 & 20,732 & -2.90 & 5.18 \\
\hline$k_{y x}$ & $\mathrm{~N} / \mathrm{m}$ & $-350,000$ & $-311,207$ & 21,843 & -11.1 & 7.28 \\
\hline$k_{y y}$ & $\mathrm{~N} / \mathrm{m}$ & 600,000 & 533,420 & 21,110 & -11.1 & 3.52 \\
\hline
\end{tabular}

The results shown here indicate that the EKF is capable of estimating the rotordynamic coefficients when the shaft motion results from imbalance and impact excitation, but conditions do not always exist where sufficient access to the shaft is available to deliver an impact to the shaft. In such cases, it would be advantageous to estimate the bearing properties with data from imbalance excitation only, for it is more common to have knowledge of the shaft residual imbalance even if it is not possible to apply a known imbalance. In this effort, the EKF filter was applied to identify the bearing properties when the system was simulated with imbalance excitation only, and the errors in the EKF estimations are shown in figure 6. Even though the errors in the direct stiffness estimates were reasonably small (less than 8 percent), the errors in the cross-coupled stiffness estimates were considerably larger, ranging from 24 to 50 percent, and the errors in the cross-coupled damping estimates were much worse ( $>100$ percent). Even after significant effort to tune the user-definable parameters, the estimates from the EKF filter could not be materially improved. The conclusion is that the EKF filter cannot estimate the bearing properties without the impact excitation present. Some parameter identification methods (Lee and Hong, 1989; Tieu and Qiu, 1994; Tiwari et al., 2002; De Santiago and San Andrés, 2007b) are capable of estimating bearing properties using imbalance excitation only, though the results are not as accurate as when impact excitation data is used. It is possible that this particular rotor-bearing problem exacerbates the inherent drawbacks with the EKF and that other Kalman filtering methods that overcome these problems, such as the Unscented Kalman Filter developed by Julier and Uhlmann (1997), may be more successful at identifying bearing parameters from imbalance response data.

It is interesting to compare the orbits computed from the (significantly incorrect!) estimated parameters and the true, noisy experimental data. One may expect that the two orbits would be noticeably different since the estimated parameters are significantly in error, but figure 7 shows that the two orbits are, instead, very close, as close as the orbits with the much more accurate bearing parameter estimates (see fig. 5). Even though the EKF cannot accurately distinguish the bearing properties individually in this case, the filter still estimates the bearing parameters collectively in such a way that the net effect of the estimated bearing properties on the shaft orbit is similar to the true effect of the actual bearing properties. Consequently, it is not advisable to use orbit comparison as a method to assess the quality of the parameter identification method. 


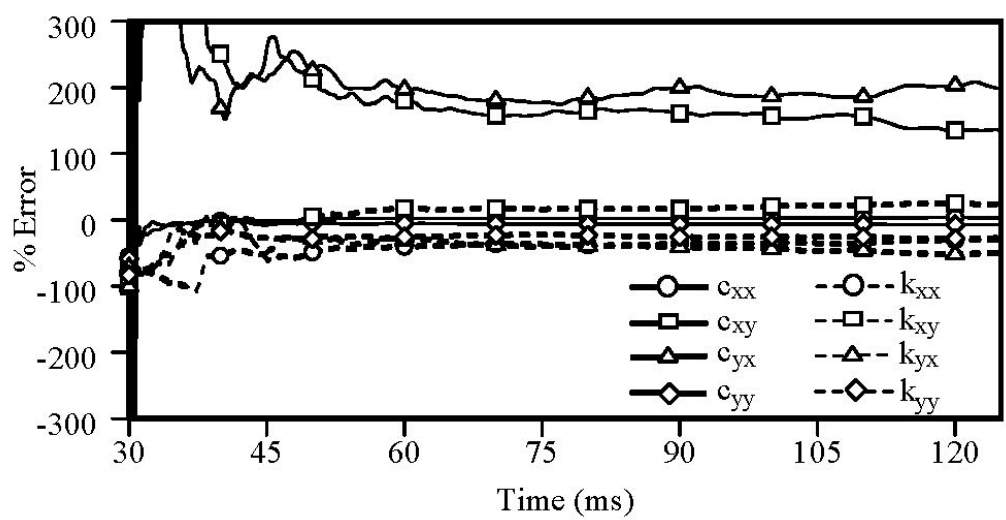

Figure 6.-Percent error in the estimated rotordynamic coefficients. The shaft was excited by imbalance only.

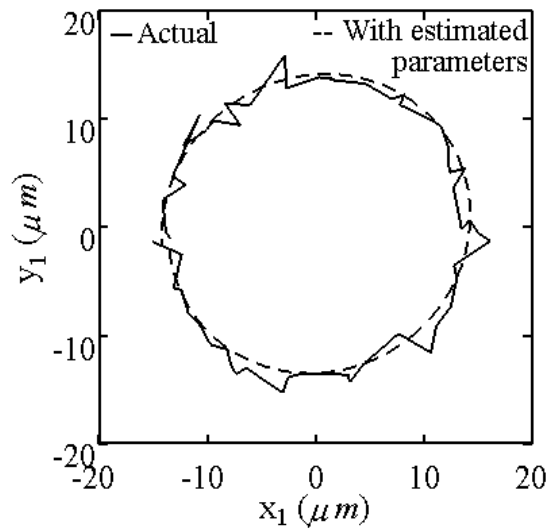

Figure 7.-One full cycle of the orbit at the turbine end. Data shown includes the actual noisy "experimental" orbit and the orbit simulated with the rotordynamic properties estimated from the simulation with only imbalance excitation.

\section{Conclusions}

This paper describes an Extended Kalman Filter (EKF) designed to identify stiffness and damping properties of two identical journal bearings from measurements of the shaft motion in a rotor-bearing system. The EKF successfully identified the rotordynamic bearing properties in numerical experiments when the shaft motion was excited by impact and imbalance, but it failed when the shaft motion was excited solely by imbalance. The filter performance was influenced marginally by user-defined tuning parameters, $\mathbf{Q}$ and $\mathbf{R}$, and more significantly by the initial values of the bearing parameters and error covariance matrix. Accuracy of the parameter estimates was similar to other published bearing parameter identification methods. Estimates for the direct damping and direct and cross-coupled stiffness values were considerably better than estimates for the cross-coupled damping values. Likewise, the relative variance in the cross-coupled damping estimates over several simulations was considerably larger than the relative variance in the direct damping and direct and cross-coupled stiffness estimates.

The paper also discusses the inadequacy of orbit comparison as a means to assess the quality of bearing parameter estimates from the EKF. When the EKF converged to a set of bearing parameter 
estimates, the shaft orbits determined analytically using those parameter estimates were close to the actual shaft orbits, regardless of the quality of the individual bearing parameter estimates.

\section{References}

DellaCorte, C., Lukaszewicz, V., Valco, M. J., Radil, K. C. and Heshmat, H. (1999), "Performance and Durability of High Temperature Foil Air Bearings for Oil-Free Turbomachinery," NASA/TM-1999209187.

DellaCorte, C. and Valco, M. J. (2000), "Load Capacity Estimation of Foil Air Journal Bearings for OilFree Turbomachinery Applications," Tribol. Trans. 43, 4, pp. 795-801.

De Santiago, O. C. and San Andrés, L. (2007a), "Field Methods for Identification of Bearing Support Parameters - Part I: Identification from Transient Rotor Dynamic Response Due to Impact,” J. Eng. Gas Turb. Power, 129, 1, pp. 205-212.

De Santiago, O. C. and San Andrés, L. (2007b), "Field Methods for Identification of Bearing Support Parameters-Part II: Identification from Rotor Dynamic Response due to Imbalances," J. Eng. Gas Turb. Power, 129, 1, pp. 213-219.

Friedland, B. (1986), "Control System Design: An Introduction to State Space Methods,” McGraw-Hill, Inc., New York, ISBN 978-0-07-022441-4.

Fritzen, C.-P. and Seibold, S. (1990), "Identification of Mechanical Systems by Means of the Extended Kalman Filter," Proc. $3^{\text {rd }}$ International Conference on Rotordynamics, IFToMM, Lyone, France, September 1990, pp. 423-429, ISBN 978-2-222-04466-6.

Gelb, A., ed., (1974), “Applied Optimal Estimation”, MIT Press, Cambridge, MA, ISBN 978-0-26270008-5.

Heshmat, H., Jahanmir, S. and Walton, J. F. (2007), "Coatings for High Temperature Foil Bearings," Paper No. GT2007-27975, Proc. ASME Turbo Expo 2007: Power for Land, Sea and Air, Montreal, Canada, May 2007, CD-ROM, American Society of Mechanical Engineers I763CD, ISBN 978-07918-3796-2.

Howard, S. A., DellaCorte, C., Valco, M. J., Prahl, J. M. and Heshmat, H. (2001), "Dynamic Stiffness and Damping Characteristics of a High-Temperature Air Foil Journal Bearing," Trib. Trans., 44, 4, pp. 657-663.

Howard, S. A. (2007), "A New High-Speed Oil-Free Turbine Engine Rotordynamic Simulator Test Rig," NASA/TM-2007-214489.

Julier, S. J. and Uhlmann, J. K. (1997), “A New Extension of the Kalman Filter to Nonlinear Systems,” Proc. AeroSense: The 11th International Symposium on Aerospace/Defense Sensing, Simulation and Controls, SPIE, Multi Sensor Fusion, Tracking and Resource Management II, Orlando, FL, April 1997, Society of Photo-Optical Instrumentation Engineers, Bellingham, WA, ISBN 978-0-81942483-9.

Lee. C.-W. and Hong. S.-W. (1989), "Identification of Bearing Dynamic Coefficients by Unbalance Response Measurements," Proc. Inst. Mech. Eng., Part C: J. Mech. Eng. Sci., 203, 2, pp. 93-101.

Murphy, B. T. and Wagner, M. N. (1991), "Measurement of Rotordynamic Coefficients for a Hydrostatic Radial Bearing," J. Trib., 113, 3, pp. 518-525.

Qiu, Z. L. and Tieu, A. K. (1997), "Identification of Sixteen Force Coefficients of Two Journal Bearings from Impulse Responses,” Wear, 212, pp. 206-212.

Roberts, J. B., Ellis, J., and Sianaki, A. H. (1990), “The Determination of Squeeze Film Dynamic Coefficients from Transient Two-Dimensional Experimental Data,” J. Lubr. Technol., 112, 2, pp. 288-298.

Sahinkaya, M. N. and Burrows, C. R. (1984), "Estimation of Linearized Oil-Film Parameters from Outof-Balance Response,” Proc. Inst. Mech. Eng., Part C: J. Mech. Eng. Sci., 198, pp. 131-135.

Salehi, M., Heshmat, H. and Walton, J. F. (2004), "Advancements in the Structural Stiffness and Damping of a Large Compliant Foil Journal Bearing: An Experimental Study,” Paper NO. GT2004- 
53860, Proc. 2004 ASME Turbo Expo: Power for Land, Sea and Air, Vienna, Austria, June 2004, CD-ROM, American Society of Mechanical Engineers I707CD, ISBN 978-0-7918-3739-9.

Tieu, A. K. and Qiu, Z. L. (1994), "Identification of Sixteen Dynamic Coefficients of Two Journal Bearings from Experimental Unbalance Responses," Wear, 177, pp. 63-69.

Tiwari, R., Lees, A. W. and Friswell, M. I. (2002), "Identification of Speed-Dependent Bearing Parameters," J. Sound Vib., 254, 5, pp. 967-986.

Tiwari, R., Lees, A. W. and Friswell, M. I. (2004), "Identification of Dynamic Bearing Parameters: A Review,” Shock Vib. Dig., 36, 2, pp. 99-124. 



\section{Appendix-Symbols}

A

C

$\mathbf{F}_{\mathbf{0}}$

G

H

I

$I_{t}, I_{p}$

$\mathbf{K}_{k}$

$L$

M

$\hat{\mathbf{P}}$

$\hat{\mathbf{P}}_{k}$

$\hat{\mathbf{P}}_{0}$

$\overline{\mathbf{P}}_{k}$

$\mathbf{Q}_{\mathrm{v}}, \mathbf{Q}_{\mathbf{z}}, \mathbf{Q}_{\mathbf{r}}$

linearization of $f$ about the current state estimate

system damping matrix

total applied forces on the shaft

system gyroscopic matrix

output matrix

identity matrix

transverse, polar shaft mass moment of inertia

Kalman gain matrix

length between the bearing centers

mass matrix

continuous-time estimate of the error covariance matrix

estimate of the error covariance matrix at time step $k$

initial estimate of the error covariance matrix

prediction of the error covariance matrix at time step $k$

covariance of the noise vectors corresponding to the shaft velocity, shaft displacement, and bearing properties

Q covariance of the global system process noise vector

$\mathbf{R} \quad$ covariance of the measurement noise vector

S system stiffness matrix

$c_{x x}, c_{x y}, c_{y x}, c_{y y}$

$d_{1}, d_{2}$

linearized bearing damping coefficients

$f$

distance from the shaft center of mass to balance plane 1, 2

$f_{b x}, f_{b y}$

nonlinear function representing the total system dynamics

$f_{x}, f_{y}$

$x, y$ direction bearing force

$g$

$x, y$ direction impact force

$k_{x x}, k_{x y}, k_{y x}, k_{y y}$

nonlinear function representing the shaft dynamics

$l_{1}, l_{2}$

linearized bearing stiffness coefficients

$m$

distance from the shaft center of mass to the centers of the bearings

$m_{1}, m_{2}$

shaft mass

$p_{1}, p_{2}$

total imbalance mass (residual and applied) at balance plane 1, 2

$r_{1}, r_{2}$

distance from the shaft center of mass to the displacement probes

$\mathbf{r}$

eccentricity of the imbalances at balance plane 1, 2

state vector of rotordynamic coefficients

$\hat{\mathbf{r}}_{0}$

$\mathbf{s}$

initial estimates of the rotordynamic coefficients

global state vector

$\mathbf{S}_{\mathbf{k}}$

global state vector at time step $k$ 


$\begin{array}{ll}\hat{\mathbf{s}} & \text { continuous-time estimate of the global state vector } \\ \hat{\mathbf{s}}_{k} & \text { estimate of the global state vector at time step } k \\ \hat{\mathbf{s}}_{0} & \text { initial estimate of the global state vector } \\ \overline{\mathbf{s}}_{k} & \text { prediction of the global state vector at time step } k \\ \mathbf{s}_{\mathbf{v}}, \mathbf{s}_{\mathbf{z}} & \text { state vector of velocity and displacement variables } \\ t & \text { time } \\ t_{k} & \text { time at time step } k \\ \mathbf{y}_{\mathbf{k}} & \text { output measurement vector at time step } k \\ \mathbf{v}_{\mathbf{k}} & \text { measurement noise vector at time step } k \\ \mathbf{w}_{\mathbf{v}}, \mathbf{w}_{\mathbf{z}}, \mathbf{w}_{\mathbf{r}} & \text { noise vectors corresponding to the shaft velocity, shaft displacement, and bearing } \\ \mathbf{w} & \text { properties } \\ x_{1}, y_{1} & \text { global system process noise vector } \\ x_{2}, y_{2} & x, y \text { shaft displacement at the bearing center near the turbine disk } \\ x_{10}, y_{10} & x, y \text { shaft displacement at the bearing center near the thrust bearing plate } \\ x_{20}, y_{20} & \text { equilibrium } x, y \text { coordinate of the shaft at the probe near the turbine disk } \\ x_{p 1}, y_{p 1} & \text { equilibrium } x, y \text { coordinate of the shaft at the probe near the thrust bearing plate } \\ x_{p 2}, y_{p 2} & x, y \text { shaft displacement at the probe near the turbine disk } \\ \mathbf{z}, \dot{\mathbf{z}}, \ddot{\mathbf{z}} & x, y \text { shaft displacement at the probe near the thrust bearing plate } \\ \mathbf{z}_{\mathbf{0}} & \text { imbalance angle measured from the reference axis at balance plane 1, } 2 \\ \dot{\mathbf{z}}_{0} & \text { initial value of the shaft displacement state vector } \\ z_{p} & \text { initial value of the shaft velocity state vector } \\ \phi_{1}, \phi_{2} & \text { distance from the shaft center of mass to the location of impact excitation } \\ \Omega & \text { imateed }\end{array}$




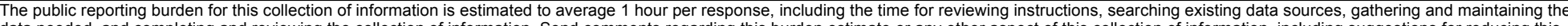

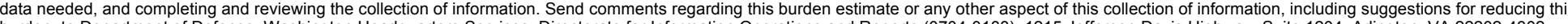

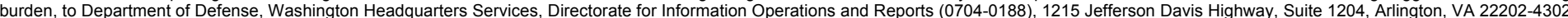

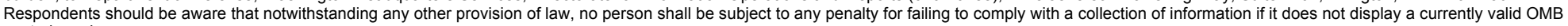
control number.

control number.
PLEASE DO NOT RETURN YOUR FORM TO THE ABOVE ADDRESS

\section{REPORT DATE (DD-MM-YYYY) \\ 2. REPORT TYPE \\ 3. DATES COVERED (From - To)}

01-08-2008

\section{TITLE AND SUBTITLE}

Technical Memorandum

Identifying Bearing Rotordynamic Coefficients Using an Extended Kalman Filter

5a. CONTRACT NUMBER

5b. GRANT NUMBER

5c. PROGRAM ELEMENT NUMBER

6. AUTHOR(S)

Miller, Brad, A.; Howard, Samuel, A.

\section{5d. PROJECT NUMBER}

5e. TASK NUMBER

5f. WORK UNIT NUMBER

WBS 877868.02.07.03.01.01

8. PERFORMING ORGANIZATION

REPORT NUMBER

E-16567

National Aeronautics and Space Administration

John H. Glenn Research Center at Lewis Field

Cleveland, Ohio 44135-3191

9. SPONSORING/MONITORING AGENCY NAME(S) AND ADDRESS(ES)

National Aeronautics and Space Administration

Washington, DC 20546-0001

10. SPONSORING/MONITORS
ACRONYM(S)
NASA
11. SPONSORING/MONITORING
REPORT NUMBER
NASA/TM-2008-215298

\section{DISTRIBUTION/AVAILABILITY STATEMENT}

Unclassified-Unlimited

Subject Category: 37

Available electronically at http://gltrs.grc.nasa.gov

This publication is available from the NASA Center for AeroSpace Information, 301-621-0390

\section{SUPPLEMENTARY NOTES}

\section{ABSTRACT}

An Extended Kalman Filter is developed to estimate the linearized direct and indirect stiffness and damping force coefficients for bearings in rotor-dynamic applications from noisy measurements of the shaft displacement in response to imbalance and impact excitation. The bearing properties are modeled as stochastic random variables using a Gauss-Markov model. Noise terms are introduced into the system model to account for all of the estimation error, including modeling errors and uncertainties and the propagation of measurement errors into the parameter estimates. The system model contains two user-defined parameters that can be tuned to improve the filter's performance; these parameters correspond to the covariance of the system and measurement noise variables. The filter is also strongly influenced by the initial values of the states and the error covariance matrix. The filter is demonstrated using numerically simulated data for a rotor-bearing system with two identical bearings, which reduces the number of unknown linear dynamic coefficients to eight. The filter estimates for the direct damping coefficients and all four stiffness coefficients correlated well with actual values, whereas the estimates for the cross-coupled damping coefficients were the least accurate.

15. SUBJECT TERMS

Gas bearings; Foil bearings; Rotor dynamics; Turbomachinery

\begin{tabular}{|c|c|c|c|c|}
\hline \multicolumn{3}{|c|}{ 16. SECURITY CLASSIFICATION OF: } & \multirow{2}{*}{$\begin{array}{l}\text { 17. LIMITATION OF } \\
\text { ABSTRACT } \\
\text { UU }\end{array}$} & \multirow{2}{*}{$\begin{array}{l}\text { 18. NUMBER } \\
\text { OF } \\
\text { PAGES } \\
21\end{array}$} \\
\hline $\begin{array}{l}\text { a. REPORT } \\
\text { U }\end{array}$ & $\begin{array}{l}\text { b. ABSTRACT } \\
\mathrm{U}\end{array}$ & $\begin{array}{l}\text { c. THIS } \\
\text { PAGE } \\
\text { U }\end{array}$ & & \\
\hline
\end{tabular}

19a. NAME OF RESPONSIBLE PERSON
STI Help Desk (email:help@sti.nasa.gov)
19b. TELEPHONE NUMBER (include area code)
301-621-0390



